\title{
Venous oxygen saturation estimation from multiple T2 maps with varying inter-echo spacing
}

Juliet Varghese ${ }^{1,2^{*}}$, Rizwan Ahmad ${ }^{3}$, Ning Jin $^{4}$, Lee C Potter ${ }^{3}$, Orlando P Simonetti ${ }^{5,6}$

From 19th Annual SCMR Scientific Sessions

Los Angeles, CA, USA. 27-30 January 2016

\section{Background}

Dependence of blood T2 on O2 saturation has led to noninvasive MRI-based techniques for determining venous $\mathrm{O} 2$ saturation $\left(\mathrm{SvO}_{2}\right)$ [1-3]. However, applying a general calibration factor derived from in vitro experiments can lead to inaccurate and largely varying $\mathrm{SvO}_{2}$ estimates in the target population. We aim to show that based on the Luz-Meiboom relation $1 / \mathrm{T} 2=1 / \mathrm{T} 2 \mathrm{o}+\operatorname{Hct}(1-\mathrm{Hct}) \tau_{\mathrm{ex}}$ $\left[\left(1-\% \mathrm{SO}_{2} / 100\right) \alpha \omega_{0}\right]^{2}\left(1-2 * \tau_{\mathrm{ex}} / \tau_{180} \tanh \left(\tau_{180} / 2 * \tau_{\mathrm{ex}}\right)\right)[4]$, individual $\mathrm{SvO}_{2}$ can be determined from multiple T2 maps, each acquired at a specific inter-echo spacing $\left(\tau_{180}\right)$.

\section{Methods}

Three T2 prepared SSFP quantitative T2 maps $\left(\tau_{180}=10\right.$, 12 and $15 \mathrm{~ms}$, TR $>3000 \mathrm{~ms}, \mathrm{FA}=40^{\circ}, 2.8 \times 2.8 \times 10$ $\mathrm{mm}^{3}, 2 \mathrm{NEX}$, free breathing) were acquired in seven volunteers (age: $32.6 \pm 12.2 \mathrm{yrs}$ ) on a $3 \mathrm{~T}$ MRI system (Tim Trio, Siemens Healthcare). T2 preparation involved an MLEV refocusing pulse train with 2, 4, 8 and 12 composite pulses. Venous and arterial blood T2 were measured in each map in an ROI in the ventricles. For each subject, the multiple $\tau_{180}$ measurements were processed jointly to estimate $\mathrm{SvO}_{2}$ along with other nuisance parameters (T2o and $\tau_{\mathrm{ex}}$ ) via constrained nonlinear least squares fitting in Matlab (The Mathworks Inc, Natick, MA, USA). The values of hematocrit (Hct), arterial $\mathrm{O} 2$ saturation $\left(\mathrm{SaO}_{2}\right)$, and $\alpha$ were fixed at $41 \%$, $97 \%$, and $0.4 \mathrm{ppm}$ respectively.

\section{Results}

Figure 1 shows T2 maps acquired in a volunteer. Table 1 shows mean $\pm \mathrm{SD}$ of venous and arterial $\mathrm{T} 2$ and

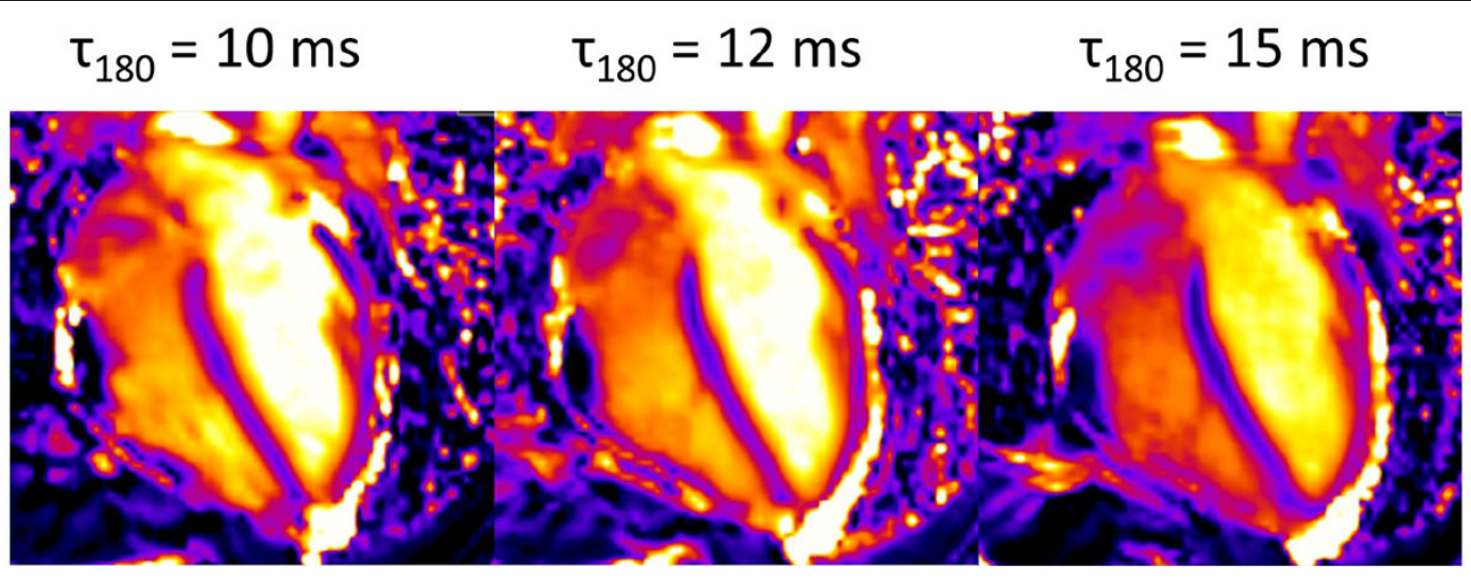

Figure 1 T2 prepared SSFP quantitative T2 maps (four-chamber view) acquired in a volunteer at different $\tau_{180}(10,12$ and 15 ms).

'Department of Biomedical Engineering, The Ohio State University,

Columbus, OH, USA

Full list of author information is available at the end of the article 
Table 1

\begin{tabular}{|c|c|c|c|c|}
\hline$\tau 180$ (ms) & TET2p (ms) & Venous T2 (ms) & Arterial T2 (ms) & Estimated Parameters \\
\hline 10 & $0,20,40,80,120$ & $125.7 \pm 11.7$ & $169.4 \pm 12.8$ & 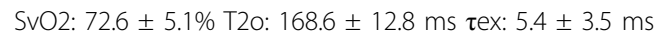 \\
\hline 12 & $0,24,48,96,144$ & $122.2 \pm 9.8$ & $176.4 \pm 22.6$ & \\
\hline 15 & $0,30,60,120$ & $110.6 \pm 13.2$ & $161.2 \pm 16.7$ & \\
\hline
\end{tabular}

The T2 preparation times (TET2p) at which T2 maps were acquired for a specific $\tau 180$, the mean \pm SD of venous and arterial $\mathrm{T} 2$ values measured in an ROI in the right and left ventricles in all volunteers, and mean \pm SD of the parameters estimated from the maps.

estimated parameters. Venous and arterial blood T2 agree with previously reported values at $3 \mathrm{~T}[2,3]$. Estimated $\mathrm{SvO}_{2}$ for all volunteers falls within the normal physiological range (60-80\%).

\section{Conclusions}

The measured $\mathrm{T} 2$ of blood is dependent on Hct, O2 saturation, and $\tau_{180}$. We have shown that if these parameters are known, $\mathrm{SvO}_{2}$ can be non-invasively determined from arterial and venous blood T2 maps acquired at multiple $\tau_{180}$. This provides in-vivo, patientspecific calibration, and may reduce the uncertainty and error in $\mathrm{SvO} 2$ estimation from applying a general calibration factor to the entire patient population. Although in this preliminary study we have assumed a fixed Hct and $\mathrm{SaO}_{2}$ for all subjects, greater accuracy may be achieved by measuring individual $\mathrm{Hct}$ and $\mathrm{SaO}_{2}$ from a blood sample and a pulse oximeter respectively. Nevertheless, our results show that the proposed approach is feasible, giving reasonable $\mathrm{SvO}_{2}$ estimates. Future studies will involve validation of the single assumed parameter, $\alpha$, in the $\mathrm{T} 2-\mathrm{SO}_{2}$ model, optimization of the set of $\tau_{180}$ times, and further evaluation of the accuracy and precision of T2 mapping in determining blood $\mathrm{O} 2$ saturation. This would lead to the development of rapid, accurate, non-invasive, in-vivo quantification of $\mathrm{SvO}_{2}$ from T2 maps, which would be highly beneficial for heart failure and congenital heart disease patients.

\footnotetext{
Authors' details Columbus, $\mathrm{OH}, \mathrm{USA}$.

Published: 27 January 2016

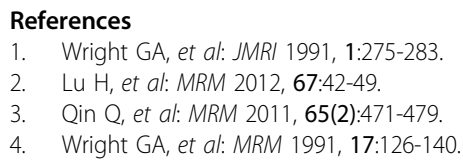

'Department of Biomedical Engineering, The Ohio State University, Columbus, OH, USA. ${ }^{2}$ Dorothy M. Davis Heart and Lung Research Institute, The Ohio State University Wexner Medical Center, Columbus, OH, USA. ${ }^{3}$ Department of Electrical and Computer Engineering, The Ohio State University, Columbus, OH, USA. ${ }^{4}$ Siemens Healthcare, Columbus, OH, USA. ${ }^{5}$ Division of Cardiovascular Medicine, Department of Internal Medicine, The Ohio State University Wexner Medical Center, Columbus, OH, USA. ${ }^{6}$ Department of Radiology, The Ohio State University Wexner Medical Center,
doi:10.1186/1532-429X-18-S1-W29

Cite this article as: Varghese et al:: Venous oxygen saturation estimation from multiple T2 maps with varying inter-echo spacing. Journal of Cardiovascular Magnetic Resonance 2016 18(Suppl 1):W29.
Submit your next manuscript to BioMed Central and take full advantage of:

- Convenient online submission

- Thorough peer review

- No space constraints or color figure charges

- Immediate publication on acceptance

- Inclusion in PubMed, CAS, Scopus and Google Scholar

- Research which is freely available for redistribution

Submit your manuscript at www.biomedcentral.com/submit
C Biomed Central 